\title{
Gambaran konsumsi makanan kariogenik pada anak SD GMIM 1 Kawangkoan
}

\author{
${ }^{1}$ Sheren Ch. M. Mendur \\ ${ }^{2}$ Damajanty H. C. Pangemanan \\ ${ }^{2}$ Christy Mintjelungan
}

\author{
${ }^{1}$ Kandidat Skripsi Program Studi Pendidikan Dokter Gigi Fakultas Kedokteran \\ ${ }^{2}$ Bagian Fisiologi Fakultas kedokteran \\ ${ }^{3}$ Program Studi Pendidikan Dokter Gigi Fakultas Kedokteran \\ Universitas Sam Ratulangi Manado \\ Email: sherenmendur@gmail.com
}

\begin{abstract}
Dental caries or tooth decay is commonly found in the society. It is caused by demineralization of enamel and dentin. Children usually have a habit of eating cariogenic foods that can cause cavities in their teeth. This study was aimed to obtain the profile of cariogenic foods consumed by the elementary school students of GMIM 1 Kawangkoan. This was a descriptive study with a cross sectional design conducted at SD GMIM 1 Kawangkoan, Minahasa. Samples were elementary school students of GMIM 1 Kawangkoan aged 6-11 years obtained by using total sampling method. Primary data were about cariogenic food consumption obtained by using food frequency questionnaire (FFQ). The results showed that there were six kinds of cariogenic foods consumed by the students, as follows: candy, chocolate wafer, chocolate bar, chocolate bread, donate cake, and pudding. According to the kategory of consumption frequency, candy belonged to very often (46.92\%); chocolate bar, often (24.93\%); chocolate bread, sometimes (20.37\%); and pudding, nearly never (33.32\%). Conclusion: The most common cariogenic food consumed by the students was candy which belonged to the very often category.
\end{abstract}

Keywords: consumption of cariogenic food, children

\begin{abstract}
Abstrak: Gigi berlubang (karies gigi) merupakan masalah yang sering ditemukan di masyarakat. Karies gigi merupakan penyakit yang disebabkan oleh demineralisasi email dan dentin. Anak-anak memiliki kebiasaan mengonsumsi makanan kariogenik yang dapat menyebabkan gigi berlubang. Penelitian ini bertujuan untuk mengetahui gambaran konsumsi makanan karogenik pada anak SD GMIM 1 Kawangkoan. Jenis penelitian ialah deskriptif dengan desain potong lintang. Penelitian dilaksanakan di SD GMIM 1 Kawangkoan Kecamatan Kawangkoan Kabupaten Minahasa. Sampel penelitian yaitu siswa SD GMIM 1 Kawangkoan berusia 6-11 tahun, diperoleh dengan menggunakan metode total sampling. Pengambilan data primer untuk melihat konsumsi makanan kariogenik melalui pengisian kuesioner menggunakan food frequency questionnaire (FFQ). Hasil penelitian menunjukkan enam jenis makanan kariogenik yang dikonsumsi, yaitu: permen, wafer coklat, coklat batang, roti coklat, donat dan puding. Berdasarkan kategori frkuensi konsumsi, permen tergolong sangat sering (46,92\%); coklat batang, sering (24,93\%); roti coklat, kadang-kadang (20,37\%); puding, hampir tidak pernah $(33,32 \%)$. Simpulan: Konsumsi makanan kariogenik paling tinggi yaitu permen yang tergolong dalam kategori sangat sering.
\end{abstract}

Kata kunci: konsumsi makanan kariogenik, anak-anak 
Gigi berlubang merupakan masalah klasik yang sejak dahulu sudah ada dan dapat dialami oleh semua orang yang masih hidup tanpa mengenal usia.. Masalah yang sering ditemui oleh dokter gigi ialah gigi berlubang. ${ }^{1}$ Anak-anak rentan terkena masalah gigi berlubang karena sifat maupun sikap yang dimiliki anak-anak yang belum mengetahui tentang pentingnya menjaga kesehatan gigi dan mulut. ${ }^{2}$

Hasil Riset kesehatan dasar (Riskesdas) tahun 2013 melaporkan bahwa prevalensi penduduk Indonesia yang memiliki masalah kesehatan pada gigi dan mulut sebanyak 25,9\%. Prevalensi terjadinya karies aktif di Indonesia masih tinggi yaitu 53,2\%. ${ }^{3}$ Karies gigi merupakan penyakit infeksi yang mengakibatkan suatu lesi berupa demineralisasi email dan dentin, yang erat hubungannya dengan konsumsi makanan kariogenik. ${ }^{4}$

Makanan kariogenik merupakan makanan manis yang mengandung gula dan sukrosa, yang dapat menyebabkan terjadinya penyakit karies gigi atau gigi berlubang. ${ }^{5}$ Makanan kariogenik merupakan makanan yang sangat digemari anakanak karena mengandung gula dan karbohidrat. Dewasa ini banyak dijumpai jenis-jenis makanan kariogenik yang bersifat manis, lunak, dan mudah melekat pada gigi seperti permen, coklat, es krim, biscuit, dan lain-lain. Selain rasanya yang manis dan enak, harganya relatif murah, mudah didapat, dan dijual dalam aneka bentuk serta warna makanan bervariasi dan disukai anak-anak. ${ }^{6}$

Gigi berlubang dapat disebabkan oleh keadaan gigi tersebut, serta makanan dan minuman yang dikonsumsi. Mengonsumsi makanan kariogenik setiap hari dalam frekuensi yang banyak dapat menyebabkan anak-anak rentan terkena masalah gigi berlubang dari pada mengonsumsi makanan kariogenik setiap hari namun dalam frekuensi konsumsi yang sedikit. ${ }^{7}$

Karies gigi jika dibiarkan akan memberi dampak negatif pada kualitas hidup anak-anak hingga beranjak remaja, bahkan sampai dewasa. Dengan mengetahui dampak dari karies gigi, sehingga dapat memberikan informasi untuk lebih memperhatikan kesehatan gigi dan mulut dengan cara mengurangi konsumsi makanan kariogenik dan rajin menyikat gigi. ${ }^{8}$ Penelitian ini bertujuan untuk mendapatkan konsumsi makanan kariogenik pada anak-anak di SD GMIM 1 Kawangkoan.

\section{METODE PENELITIAN}

Jenis penelitian ialah deksriptif dengan desain potong lintang. Penelitian dilakukan di SD GMIM 1 Kawangkoan Kecamatan Kawangkoan Kabupaten Minahasa pada bulan Agustus 2016. Populasi pada penelitian yaitu seluruh anak di SD GMIM 1 Kawangkoan berusia 6-11 tahun dengan jumlah 103 siswa. Pengambilan sampel menggunakan metode total sampling dan memenuhi kriteria inklusi dan eksklusi mendapatkan 54 anak.

Sebelum melakukan penelitian, peneliti telah melakukan survei awal dan permohonan ijin kepada kepala sekolah lewat surat permohonan ijin. Surat survei awal yang dibuat oleh bagian administrasi Program Studi Pendidikan Dokter Gigi Unsrat. Anak-anak sekolah yang dilakukan pengambilan data dimintakan ijin tertulis berupa informed consent kepada orang tua sebelum penelitian dilakukan.

Data primer diperoleh secara langsung saat penelitian di SD GMIM 1 Kawangkoan melalui pengisian lembar kuesioner Food Frequency Questioner (FFQ). Data Sekunder diperoleh dari profil sekolah berupa identitas dan jumlah siswasiswi di SD GMIM 1 Kawangkoan.

Data diolah berdasarkan istribusi frekuensi dan disajikan dalam bentuk tabel dan dianalisis secara deskriptif berdasarkan persentase.

\section{HASIL PENELITIAN DAN BAHASAN}

SD GMIM 1 Kawangkoan terletak di Kelurahan Sendangan, Kecamatan Kawangkoan Kabupaten Minahasa. Responden penelitian ialah anak-anak sekolah dasar usia 6-11 tahun sebanyak 54 anak yang terdiri dari 30 anak $(55,56 \%)$ berjenis kelamin laki-laki dan 24 anak 
$(44,44 \%)$ berjenis kelamin perempuan (Tabel 1).

Tabel 1. Distribusi responden penelitian berdasarkan jenis kelamin

\begin{tabular}{clc}
\hline Jenis kelamin & (n) & $(\boldsymbol{\%})$ \\
\hline Laki-laki & 30 & 55,56 \\
Perempuan & 24 & 44,44 \\
Total & 54 & 100 \\
\hline
\end{tabular}

Responden berusia 6-8 tahun berjumlah 17 anak $(31,48 \%)$, sedangkan yang berusia 9-11 tahun berjumlah 37 anak $(68,52 \%)$ (Tabel 2).

Tabel 2. Distribusi responden penelitian berdasarkan usia

\begin{tabular}{ccc}
\hline $\begin{array}{c}\text { Usia } \\
\text { (tahun) }\end{array}$ & $(\mathbf{n})$ & $\mathbf{( \% )}$ \\
\hline $6-8$ & 17 & 31,48 \\
$9-11$ & 37 & 68,52 \\
Total & 54 & 100 \\
\hline
\end{tabular}

Data tentang konsumsi makanan (permen, coklat batang, roti coklat, kue donat, wafer coklat, dan puding) diperoleh melalui food frequency questionnaire. Distribusi frekuensi konsumsi makanan dibagi dalam 5 kategori yaitu sangat sering, sering, kadang-kadang, hampir tidak pernah, dan tidak pernah.

Berdasarkan hasil konsumsi makanan kariogenik (Tabel 3) didapatkan makanan kariogenik yang paling sering dikonsumsi yaitu: permen $\geq 2$ kali sehari dengan kategori sangat sering (46,29\%); makanan kariogenik dengan kategori sering yaitu coklat batang (24,93\%); makanan kariogenik dengan kategori kadang-kadang yaitu roti coklat (20,37\%); makanan kariogenik yang dikonsumsi hampir tidak pernah yaitu puding $(33,32 \%)$. Konsumsi makanan kariogenik yang masuk dalam kategori konsumsi paling sedikit yaitu 1 kali sebulan dengan kategori tidak pernah yaitu puding $(40,74 \%)$.

Tabel 3. Distribusi frekuensi konsumsi makanan kariogenik

\begin{tabular}{|c|c|c|c|c|c|c|c|c|c|c|}
\hline \multicolumn{11}{|c|}{ Frekuensi Konsumsi Makanan Kariogenik } \\
\hline Jenis & \multirow{2}{*}{\multicolumn{2}{|c|}{$\begin{array}{l}\text { Sekali } \\
\text { sehari }\end{array}$}} & \multirow{2}{*}{\multicolumn{2}{|c|}{$\begin{array}{l}\geq 2 \text { kali } \\
\text { sehari }\end{array}$}} & \multirow{2}{*}{\multicolumn{2}{|c|}{$\begin{array}{c}\text { Beberapa } \\
\text { kali seminggu }\end{array}$}} & \multirow{2}{*}{\multicolumn{2}{|c|}{$\begin{array}{l}1 \text { kali } \\
\text { seminggu }\end{array}$}} & \multirow{2}{*}{\multicolumn{2}{|c|}{$\begin{array}{l}1 \text { kali } \\
\text { sebulan }\end{array}$}} \\
\hline Makanan & & & & & & & & & & \\
\hline & $\mathrm{n}$ & $\%$ & $\mathrm{n}$ & $\%$ & $\mathrm{n}$ & $\%$ & $\mathrm{n}$ & $\%$ & $\mathrm{n}$ & $\%$ \\
\hline Permen & 12 & 22,22 & 25 & 46,92 & 7 & 12,96 & 6 & 11,11 & 4 & 7,42 \\
\hline Coklat batang & 14 & 24,93 & 18 & 33,33 & 8 & 14,81 & 10 & 18,51 & 4 & 8,42 \\
\hline Roti coklat & 11 & 20,37 & 7 & 12,96 & 11 & 20,37 & 14 & 25,93 & 11 & 20,37 \\
\hline Kue donat & 10 & 18,51 & 4 & 7,42 & 5 & 9,25 & 14 & 25,93 & 21 & 38,89 \\
\hline Wafer coklat & 11 & 20,37 & 19 & 35,18 & 9 & 16,67 & 6 & 11,11 & 9 & 16,67 \\
\hline Puding & 4 & 7,42 & 2 & 3,70 & 8 & 14,82 & 18 & 33,32 & 22 & 40,74 \\
\hline
\end{tabular}

Penelitian ini dilakukan pada 54 responden dengan karakteristik yang dikelompokkan berdasarkan jenis kelamin dan usia. Berdasarkan hasil penelitian responden berjenis kelamin laki-laki lebih banyak dari pada responden berjenis kelamin perempuan. Berdasarkan usia responden yang diteliti terdapat 3 anak yang berusia 6 tahun $(5,56 \%), 5$ anak berusia 7 tahun $(9,25 \%), 9$ anak berusia 8 
tahun $(16,67 \%), 11$ anak berusia 9 tahun $(16,67 \%), \quad 14$ anak berusia 10 tahun $(25,93 \%)$, dan 12 anak berusia 11 tahun $(22,22 \%)$.

Berdasarkan survei yang telah dilakukan oleh peneliti sebelum melakukan penelitian terdapat enam jenis makanan kariogenik yang di konsumsi oleh anakanak di SD GMIM 1 Kawangkoan, makanan yaitu permen, coklat batang, roti coklat, kue donat, wafer coklat, dan puding. Jenis-jenis makanan ini dijual di kantin sekolah.

Dari hasil penelitian yang telah dilakukan didapatkan konsumsi makanan kariogenik paling tinggi yaitu permen, dengan konsumsi sebanyak $\geq 2$ kali sehari termasuk dalam kategori sangat sering $(46,25 \%)$, dan kategori konsumsi makanan kariogenik paling rendah yaitu puding dengan konsumsi 1 kali sebulan termasuk dalam kategori tidak pernah yaitu $(40,74 \%)$. Permen merupakan jenis makanan yang paling sering dikonsumsi oleh anak-anak dan dikonsumsi lebih dari dua kali sehari. Permen berbahan dasar gula, dan ketika dikonsumsi melekat pada gigi. ${ }^{9}$

Hal ini menunjukkan bahwa anak-anak lebih senang untuk mengonsumsi makanan kariogenik. ${ }^{10}$ Alasan tersebut dikarenakan makanan kariogenik lebih nikmat dimakan, banyak dan mudah ditemukan, tanpa mengetahui dampak yang diakibatkan oleh mengonsumsi makanan kariogenik tersebut. ${ }^{11}$

Makanan-makanan ini jika sering di konsumsi setiap hari dapat menyebabkan kerusakan pada gigi dan menyebabkan karies gigi atau gigi berlubang. ${ }^{12}$ Hasil penelitian ini hampir serupa dengan hasil penelitian Indry $^{13}$ yang menunjukkan bahwa kelebihan mengonsumsi makanan kariogenik dapat menyebabkan kerusakan gigi. Umumnya jenis makanan kariogenik yang menyebabkan kerusakan gigi ialah permen, coklat, kue, dan wafer, yang selalu tersedia di kantin sekolah, bahkan di daerah sekitar mereka tinggal, yang dapat dijangkau oleh anak-anak. Karena rasanya yang enak dan memberi rasa kenyang, sehingga disukai oleh anak-anak. ${ }^{14}$

Hasil wawancara melalui kuesioner konsumsi makanan kariogenik di SD GMIM 1 Kawangkoan rata-rata siswa-siswi mengonsumsi makanan kariogenik lebih dari dua kali sehari, dengan frekuensi konsumsi yang berbeda-beda. Walaupun mengonsumsi makanan kariogenik lebih dari dua kali sehari, anak-anak di SD GMIM 1 Kawangkoan umumnya rajin menyikat gigi dua kali sehari yang dapat mengurangi kerusakan pada gigi.

Penelitian ini hampir serupa dengan hasil penelitian Iwan ${ }^{15}$ yang menyatakan bahwa kelebihan mengonsumsi jajanan atau makanan kariogenik dengan frekuensi konsumsi yang banyak menyebabkan masalah kesehatan pada gigi. ${ }^{15}$ Frekuensi sangat memengaruhi proses demineralisasi dan remineralisasi. Asam yang terbentuk oleh makanan akan menurunkan $\mathrm{pH}$ rongga mulut sehingga terjadi suasana asam dan dampaknya yaitu proses demineralisasi. Proses demineralisasi akan menyebabkan email gigi kehilangan ion kristalisasi sehingga keterpaparan gigi sangatlah tinggi. ${ }^{16}$ Semakin sering anak mengonsumsi makanan yang mengandung karbohidrat terutama sukrosa akan mengakibatkan keadaan mulut menjadi asam sehingga semakin besar kemungkinan demineralisasi email terjadi pada gigi dan menyebabkan terjadinya karies. ${ }^{17}$

\section{SIMPULAN}

Terdapat enam jenis makanan kariogenik yang di konsumsi anak-anak SD GMIM 1 Kawangkoan yaitu, permen, coklat batang, kue donat, wafer coklat, roti coklat dan puding. Konsumsi makanan kariogenik paling tinggi yaitu permen dengan frekuensi konsumsi lebih dari dua kali sehari yang termasuk dalam kategori sangat sering.

\section{SARAN}

Bagi sekolah disarankan baik guruguru maupun siswa-siswi untuk meningkatkan program promotif dan preventif di bidang kesehatan khususnya kesehatan gigi dan mulut. 
DAFTAR PUSTAKA

1. Hidayanti L. Hubungan karakteristik keluarga dan kebiasaan konsumsi makanan kariogenik dengan keparahan karies gigi anak sekolah dasar. Semarang. [cited 2016 Aug]. Available from: URL:http://eprints.undip.ac.id./8535/1/ LILIK.pdf.

2. Materi Penyuluhan. Available from: http://repository.usu.ac.id/bitstream/12 3456789/51638/1/Appendix.pdf

3. Badan Penelitian dan Pengembangan Kesehatan. Riset Kesehatan Dasar (Riskesdas) 2013. Jakarta: Kementrian Kesehatan RI, 2013; p. 110-1.

4. Arvin B. Karies gigi pada anak. Ilmu Kesehatan Anak. 2012. [cited 2016 March]. Available from: URL: hhtp://ilmukesehatangigi.com.

5. Kartaesapoetra G, Marsety H. Ilmu Gizi. Jakarta: Rineka Cipta, 2010; p. 73.

6. Cakrawati D. Bahan Pangan Gizi dan Kesehatan. Bandung: Alfabeta, 2012; p. 66-7.

7. Sariningsih E. Merawat Gigi Anak Sejak Dini. Jakarta: Elekmedia Komputindo Kelompok Gramedia, 2012; p. 32.

8. Yusuf S. Psikologi Perkembangan Anak dan Remaja (8th ed). Bandung: Remaja Ruskarya, 2007; p. 11.

9. Indah Z. Penyakit Gigi, Mulut, dan THT. Yogyakarta: Nuha Medika, 2014; p. 62.

10. Hutagalung H. Karbohidrat. [cited 2016 Sept]. Available from: URL: http//www.library.usu.ac.id.

11. Maulani. Kiat Merawat Gigi Anak. Jakarta:
Gramedia, 2005.

12. Eva DS. Pengaruh konsumsi makanan kariogenik dan kebiasaan menyikat gigi terhadap kejadian karies gigi molar pertama permanen pada anak usia 9-11 tahun di SDN Blimbing 01 Kecamatan Gatak Kabupaten Sukoharjo. [cited 2016 Sept]. Available from: http://eprints.ums.as.id/44930/13/NAS PUB.pdf.

13. Indry W. Pengalaman karies gigi serta pola makan dan minum pada anak sekolah dasar di Desa Kiawa Kecamatan Kawangkoan Utara [Skripsi]. Manado: Universitas Sam Ratulangi; 2012.

14. Touger R, Loveren CV. Sugars and dental caries. Am J Clin Nutr. 2003;78:881S892S.

15. Iwan W. Hubungan konsumsi jajanan dan status karies gigi siswa di SMP Negeri 1 Tareran. [cited 2016 Oct]. Available from:

http://ejournal.unsrat.ac.id/index.php/e gigi/article/view/10812.

16. Soegeng S, Anne LR. Kesehatan dan Gigi. Jakarta: Rineka Cipta dan Bina Adiaksara, 2009; p.18.

17. Novan AKM. Pengaruh mengunyah buah stroberi terhadap hambatan pembentukan plak gigi pada remaja usia 12-18 tahun di panti asuhan Yayasan Nur Hidayah Kota Surakarta. [cited 2016 Oct]. Available from: http://eprints.ums.ac.id/31236/12/10.N ASKAH_PUBLIKASI.pdf. 